\title{
AC 2011-2377: TWEAKING PRODUCT DESIGN AND DEVELOPMENT
}

\section{Bill Crockford, Sam Houston State University}

He is a registered engineer in Texas. Work experience includes research on flexible pavement materials, design, manufacture and instrumentation of closed loop testing machines, remote sensing, aviation related positions, and a NASA/JSC Advanced Programs Office summer fellowship involving lunar base construction. He holds utility patents as sole inventor. His current work is with Industrial Technology students in construction, product design and manufacturing, and electronics programs.

\section{Bruce Hamby, The Hamby Law Firm}

Bruce W. Hamby is a Registered Patent Attorney in the United States. He graduated from law school at the University of Illinois at Urbana-Champaign with a J.D. and earned his B.S. in Professional Chemistry (with a Biology minor) at Sam Houston State University. Mr. Hamby has practiced law as both a transactional attorney and a litigation attorney in California and Texas; he can be reached at brucehamby@hambylaw.com. 


\title{
Tweaking Product Design and Development
}

\begin{abstract}
New faculty faced with preparation for a course in product design and development must address a wide range of topics ranging from entrepreneurship to hard core engineering. Some resources available to the faculty are heavy on the business side of the problem and somewhat lighter on the technological and engineering side. To more effectively balance these topics, tweaking of available resources must be done. In general, these types of courses involve a project that produces a 3D solid computer model of the product, or a physical prototype. An inevitable consequence of this is that either existing products must be designed (actually copied) for the project, or intellectual property must be considered. This paper discusses three areas of refinement to commonly available resources, two of which are technical in nature and one of which is entrepreneurial. They are: (1) enhancement of engineering considerations in computer modeling, (2) emphasis on manufacturing with an eye toward restoring a competitive North American manufacturing base, and (3) handling the issue of intellectual property when innovation is desired as part of the project.
\end{abstract}

Students in Industrial Technology and Engineering Technology may not be exposed to the same level of mathematical rigor as straight discipline-specific Engineering majors. However, they often use the same tools as the Engineer once they are in the workforce. Industrial design students should understand some of the background and implications of their designs that can come out of the design programs that their employer may require them to use in order to avoid the problem of designing in a vacuum. We address this by going into some detail in two areas of usage of typical design programs such as SolidWorks: stress concentration and material selection. While this can be done without the computer, it is most effective if a 3D program is available to all students and that program has the capability to do three things: model assemblies, specify or select engineering material properties of the components, and perform finite element analyses.

The North American manufacturing base was exported off-shore primarily in response to relatively short-sighted profit maximization considerations. This may actually turn out to have been a negative net present value approach when other factors of more long term consequence are considered. Lean manufacturing (and modified versions thereof) and automation are tools that can be used to help improve manufacturing competitiveness.

In at least one well-known resource, the authors of the textbook say that they do not wish to be bound by the constraints of intellectual property management in a course. A key internal motivator for students is that flicker of light when they have seen that they can do something that is meaningful, possible, innovative and theirs. While one approach is to assign a project, and another is to limit the course to public domain prior art in an effort to avoid intellectual property issues, we find it to be a more effective student motivator to allow innovation that could result in valuable intellectual property for the student. 


\section{Introduction}

In a broad product design and development course, the new instructor in a technology based program may find resources to use in the classroom that effectively cover that resource's intended breadth of the body of knowledge, but could benefit from more focused coverage in the instructor's local program technological areas. An objective of this paper is to report experiences and provide some guidance on such coverage. Three focal points are discussed: (1) engineering factors with an emphasis on materials and geometric considerations as they relate to solid modeling and product performance, (2) manufacturing processes and concepts of lean manufacturing as they relate to both pre-production design/prototyping and final product manufacturing efficiency, and (3) intellectual property. We identify some techniques for providing enhanced coverage of these points, some basic ideas for handling individual measurements in the presence of group or team project scenarios, and an instrument that enables intellectual property and innovation to be dealt with in the classroom. Coverage in each of the three areas is directed toward both classroom experiences for the student directly related to the course content, and translation of those experiences into student capabilities that will be useful in an industrial/technological career. The intellectual property component of the paper includes a non-disclosure agreement (NDA) in both long and short forms intended to be used in the classroom to help the instructor open the classroom up to real world innovation with real world intellectual property consequences. The document is intended not only to turn the classroom into a miniature "think tank", but to expose the students to a legal instrument similar to the first one they will see when they become a "key employee" of a technical firm that is involved in developing products backed by intellectual property assets.

Enhancing ("tweaking") a course in product design and development presupposes a fundamental platform ("kernel") upon which the enhancement will build. The kernel used for this discussion is in the form of a textbook ${ }^{1}$. In the on-line resources ${ }^{2}$ for this text, various approaches to teaching the course are discussed. One of those approaches involves using the entire book, and we did so in a semester long industrial technology course as part of a design program curriculum. Additional resources ${ }^{3,4,5,6,7,8,9}$ can be used to enhance this work. In particular, lean manufacturing topics ${ }^{3,4}$ were addressed in the first half of the course, and engineering topics were scattered throughout the course. The bold, italicized topics from the kernel shown in Fig. 1 are the targets of the enhancement as shown in Fig. 2. A basic timeline is shown in Fig. 3 (randomly broken into three parts only to fit manuscript format limitations).

Planned obsolescence is sometimes considered a necessary business tactic for profit maximization or even survival. In the course, we assume that the student will grasp enough of the general entrepreneurial business concepts such as time value of money that they will understand the implications of product life cycle and time to market on the business. Here, we do not treat planned obsolescence. Therefore, we assume that the intent of design is to extend the life of the product to the maximum possible within budgetary constraints, and even in some cases without those constraints, in order to show what might be possible with "unlimited" budgets. However, materials and processing costs are considered during the course. 


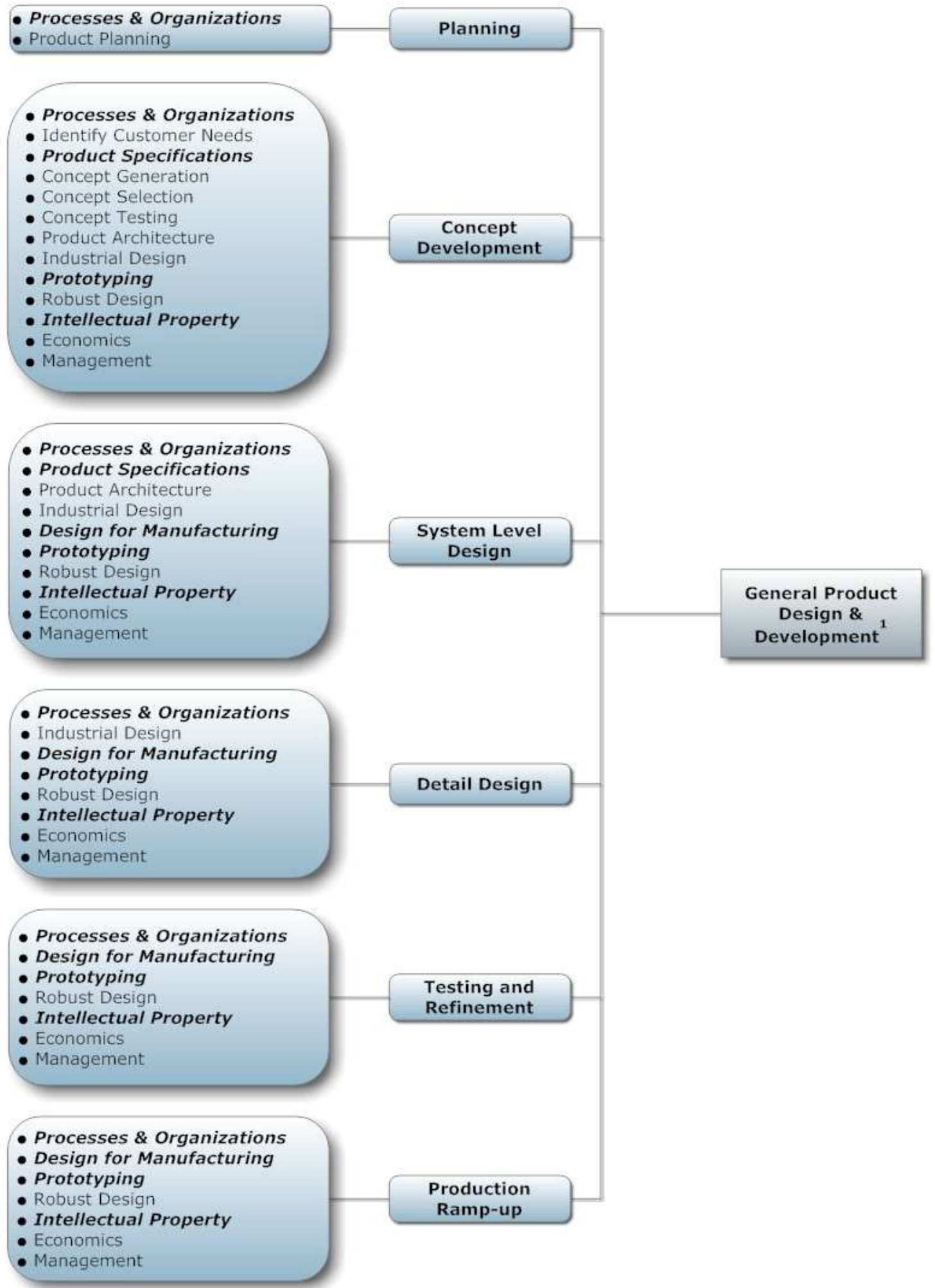

Figure 1. General Product Design and Development structure ${ }^{1}$. 


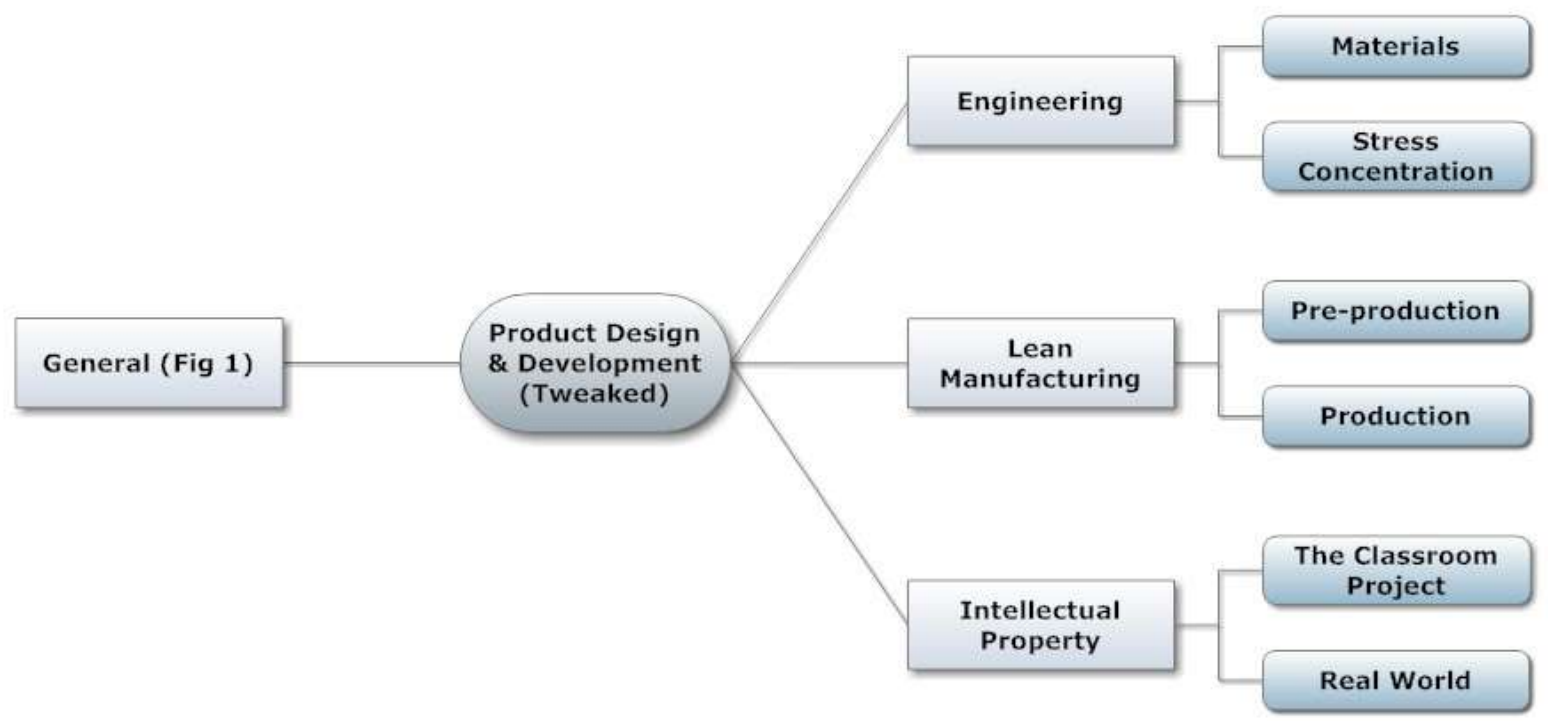

Figure 2. Enhancement of general kernel structure, concentrating on italicized subjects in Fig 1.

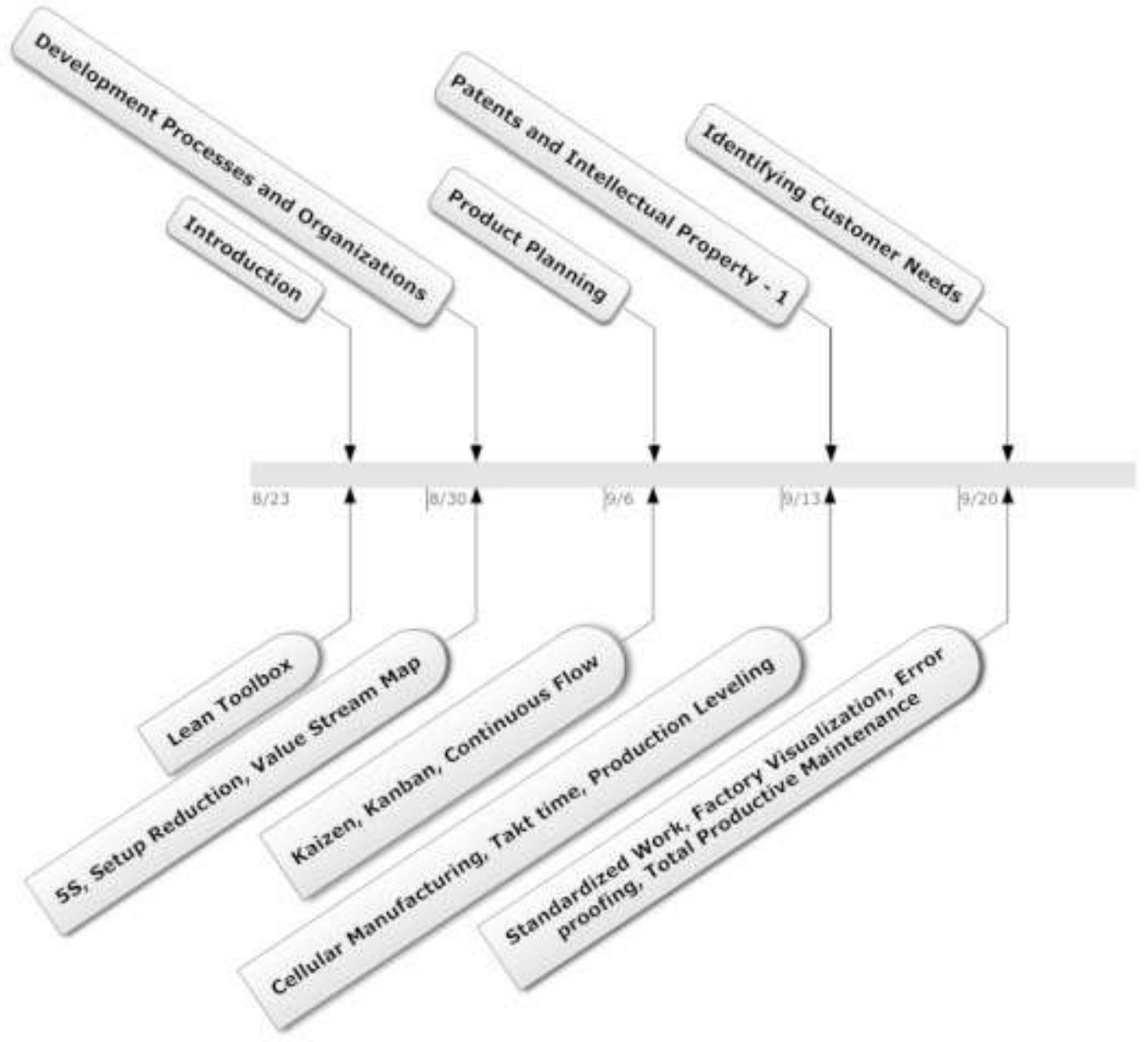

Fig 3a 


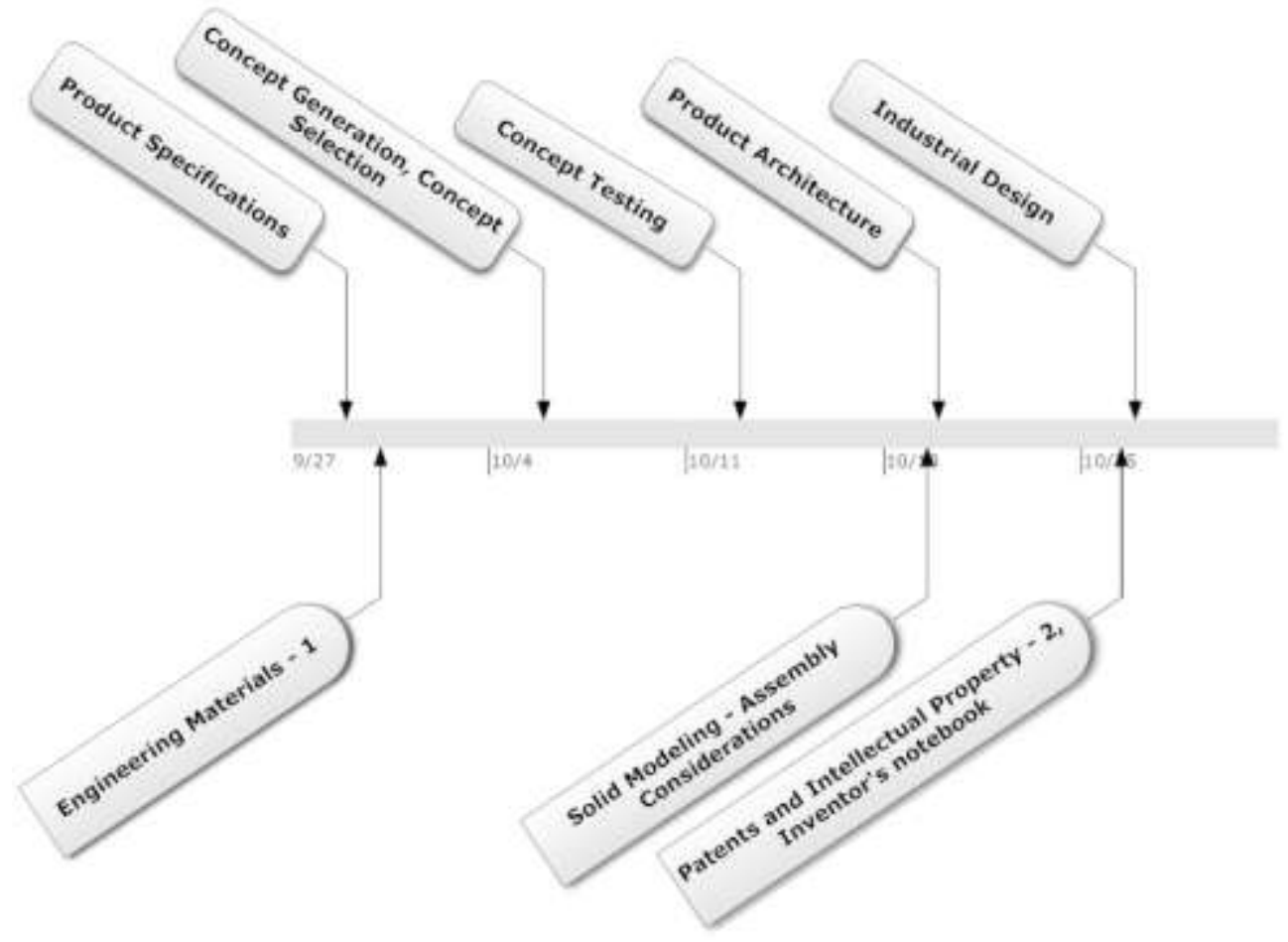

Fig 3b (above), 3c (below)

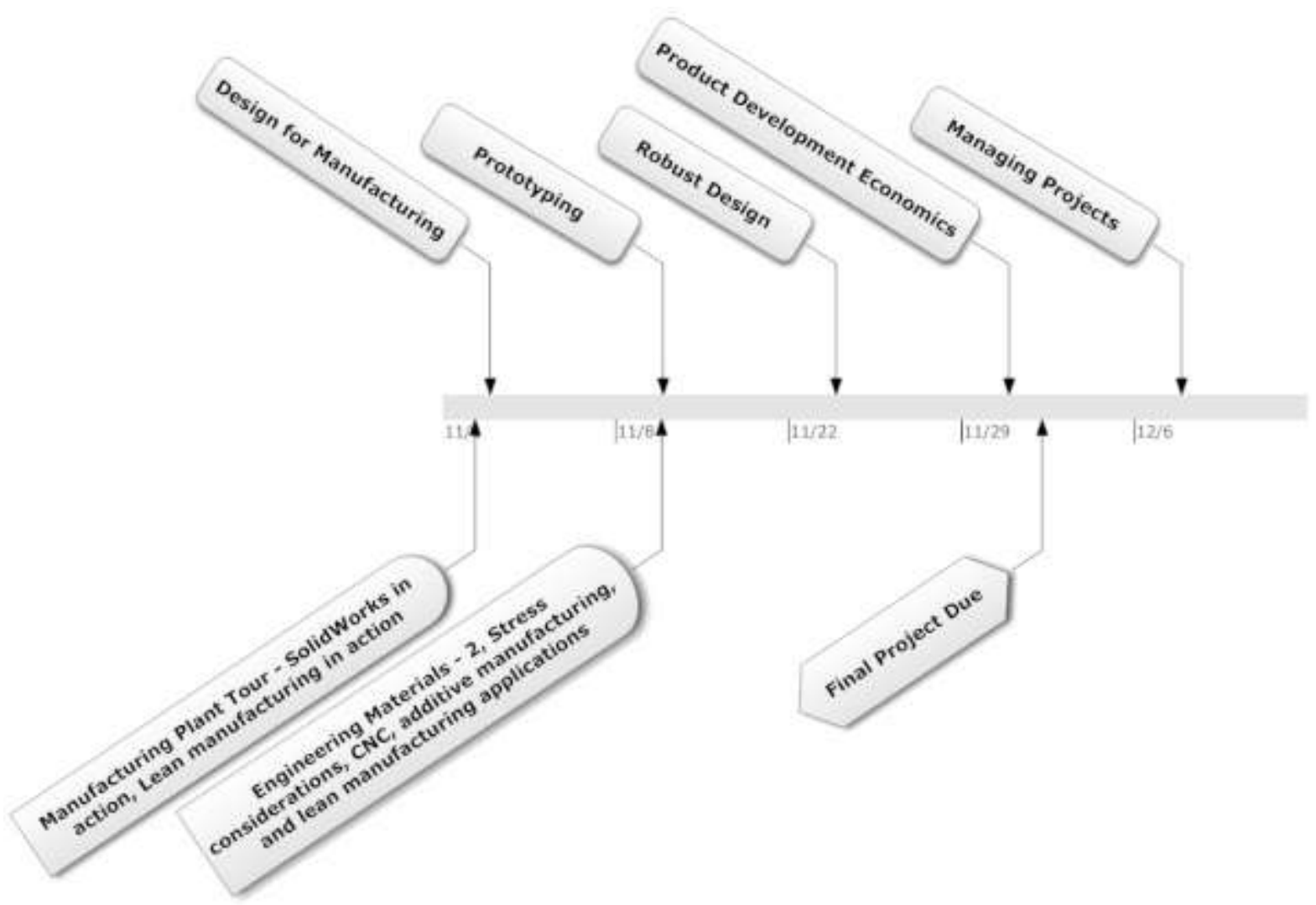

Figure 3. Course timeline (subjects above timeline comprise kernel, below timeline comprise enhancement). 


\section{Engineering Enhancement-Materials}

Are polymers friends or foes? There are many applications for which polymers are not the correct choice of material, yet they are still used. Some of these applications could effectively use polymers, but the incorrect composition is often used, in some cases because of raw material costs and in others because of manufacturing process cost, or perhaps because of inadequate design considerations. Two common compositional factors used to optimize mechanical behavior of polymers are molecular weight (or "mass") and cross-linking. In general, these factors alter the viscoelastic behavior of the material. This leads us to our first enhancement goal: raw material considerations for product applications.

For the technology student in a first course on product design and development, the concept of viscoelasticity may be a foreign one. Because the course is not a materials course, the student should be exposed to mechanical behavior concepts by meeting them at their entry level of experience and help them reach a level at which they know the concepts or at least know when to ask questions or do further research on a particular problem after they enter the workforce. For this reason, we limit discussions to mechanical behavior of three groups of materials: (1) metals, (2) glass, and (3) polymers, and to two basic behavior concepts: (1) pre-failure and (2) failure. For example, to illustrate viscoelasticity and time-temperature superposition, we use the common example of a ball of "Silly Putty®", showing that it can bounce (high frequency/low temperature behavior) and retain its shape, or deform very slowly under its own weight or body forces (low frequency/high temperature behavior) when the ball is left to its own devices on a desk for the period of a lecture.

The two basic behaviors mentioned above translate to classroom experience in this course with exposure to two properties: modulus and strength. There is more to engineering materials behavior than these two properties can fully define, but they comprise a good starting point for the technology student. Students are encouraged to explore the internet ${ }^{9}$ with regard to this subject. All plastics are not created equal, and through some internet searching, the student will discover a huge number of brand names and polymer formulations that cover a wide range of material properties. A useful tool to explore the effects of these properties on prototypes and finished products can be found in solid modeling software such as SolidWorks. Although SolidWorks can perform finite element models of assemblies, at the level and coverage of this course, stress analysis of an individual part is sufficient to illustrate basic concepts. Multiple scenarios can be conducted in short order using the materials database in SolidWorks, and custom materials can be developed by the user. Figure 4 illustrates the materials interface in SolidWorks 2011. Changing materials categories (e.g. from plastics to aluminum alloys), or from material to material within a category, can produce significantly different results in deformation and performance of parts, prototypes and finished products. This becomes apparent when one conducts multiple analyses with widely varying properties for elastic modulus, and tensile and yield strength. In a product design course of this scope and target student, it is sufficient to limit exposure in solid modeling to linear elastic isotropic conditions. 


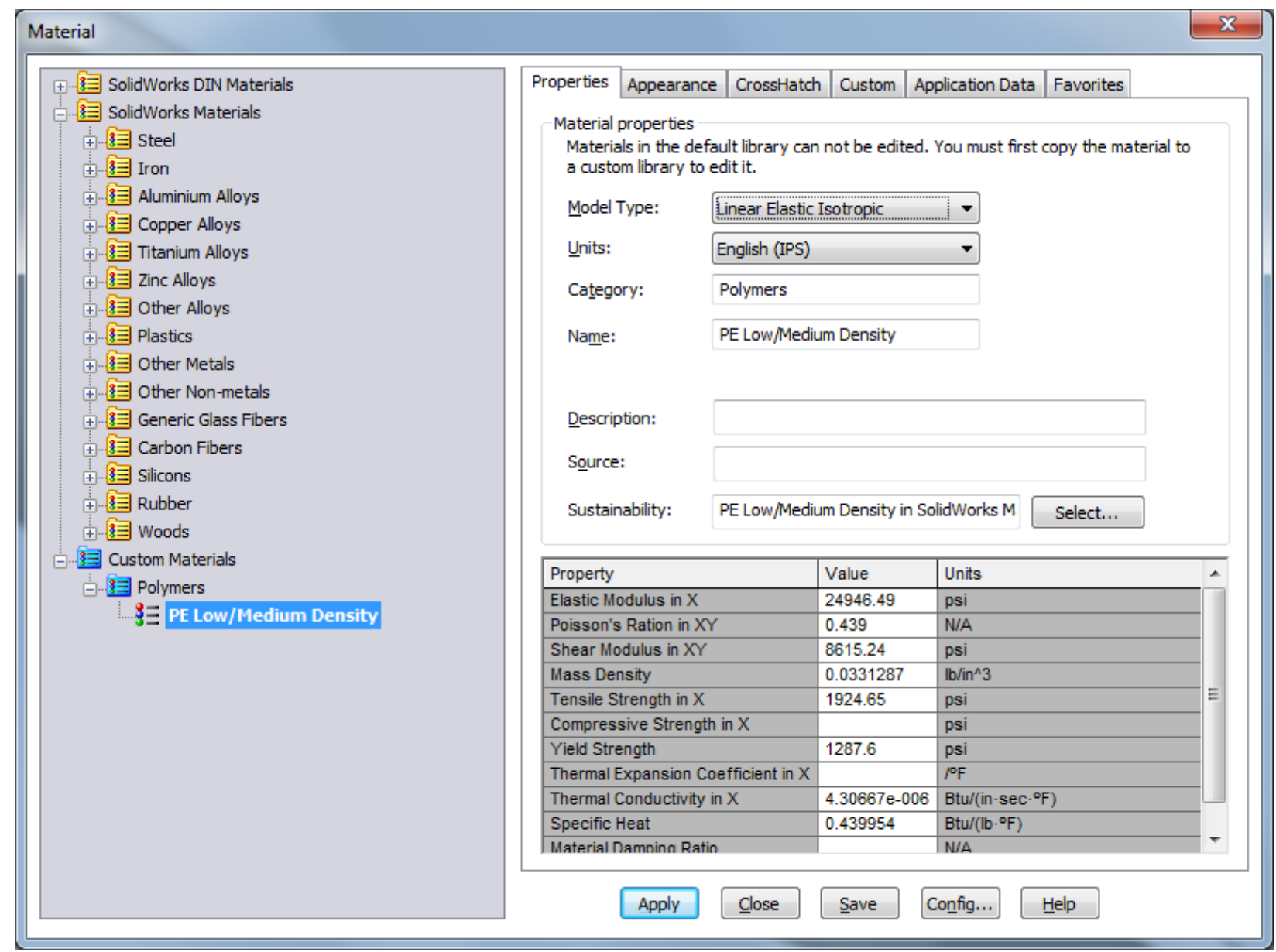

Figure 4. SolidWorks 2011 materials database user interface.

\section{Engineering Enhancement - Stress Concentration}

With a sheet of silicon RTV, one can demonstrate the effect of stress concentration. However the same result can be obtained with a sheet of paper or shrink wrap by pulling on it when there are no flaws in it, followed by cutting a slit in it and pulling perpendicular to the slit. Generally, this reinforces the obvious for the student, but when discussions of sharp $90^{\circ}$ corners are then introduced, the student should start thinking about how curves versus intersecting straight lines might make the part or assembly behave under stress. In this way, the instructor opens the door to the option of introducing the mathematical background of stress concentration factors around circular holes, elliptical holes and sharp cracks, and fracture toughness, or to simply leave it at the level of basic observation of a physical phenomenon. For the technology student in an early course in product design, the physical concept of stress concentration and a notion of a range and trend toward rapid stress increase as the flaw sharpens may be a sufficient level of understanding which can then be emphasized with physical demonstration and CAD finite element analyses. 
On a routine basis, one can find examples of cases in which a designer has specified a sharp corner in a plastic part for which it is difficult to manufacture the mold because it calls for very small diameter tools and/or instantaneous changes in machining direction by $90^{\circ}$ or more (although the outer packaging that constitutes "eye candy" for the consumer has tended toward fewer external sharp corners over the years). Further examples of the lack of consideration of stress concentration can be found in hole applications like integral "pillow blocks" for pivot pins. Some examples might be found in self-latching slide-to-open battery compartments, spring loaded hinged latches like belt holsters for electronic devices, and similar products. Often, sharp corners are unnecessary and even unwanted. So the cost of the manufacturing process becomes unnecessarily inflated and the product life is deflated if sharp corners are retained, even though it would take very little in the way of design changes to reduce the stress concentration factor and simultaneously increase fatigue life. A simple example that might constitute a portion of something like a latch on a battery compartment cover is shown in Figure 5.
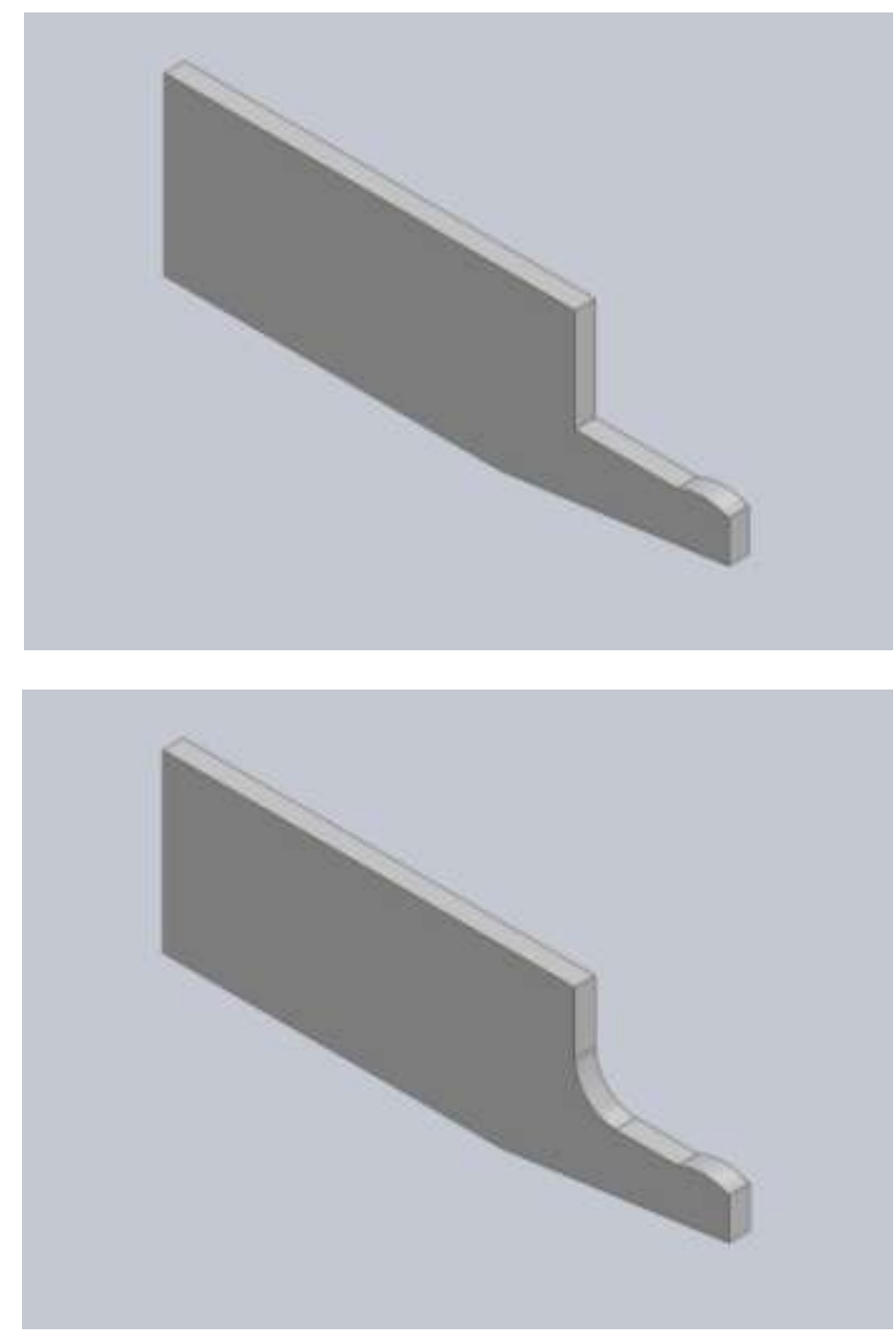

Figure 5. Simple example of reduction of stress concentration by replacement of a sharp corner (top) with a radius. 


\section{Engineering Enhancement - Coupling Materials and Stress-Strain Concepts}

In many educational settings, addressing the issue of design for minimization of stress and strain or maximization of factor of safety with some other constraint such as mass or dimension is relatively simple because solid modeling software may be readily available. However, it is sometimes more challenging to address the materials component. In many institutions, equipment that can handle only certain types of materials is available. Our approach was to use additive manufacturing for some of the student projects that were small enough (i.e. would fit in the machine). Some of the more affordable additive manufacturing equipment (e.g. "3D printers") are limited to one material, plastic, such as a type of ABS plastic. Our situation is that we are currently limited to one type (and color) of plastic in our solid model prototypes (although we also have a conventional machine shop that enables the use of materials such as wood, aluminum and steel for prototyping). Our approach therefore is to discuss materials in a classroom setting for "book knowledge", and to leave the 3D printer physical prototyping to demonstration of the product and implementation of good design practices for enhancing product life cycle and marketability.

In the previous sections, we have discussed material properties and part geometry. The integration of those two subject areas comes into play during finite element analysis. Here, we discuss the SolidWorks embedded finite element modeling approach ("SimulationXpress"). Even in the basic edition of SolidWorks, limited finite element analyses can be performed. The limitations come from three things: (1) boundary conditions, (2) constitutive models, and (3) mesh generation.

In the stripped down version of finite element analysis (FEA), SolidWorks allows only fixed displacement boundary conditions on a surface. Access to individual nodes, specified directions of individual displacement boundary conditions and features such as spring/damped boundary conditions sometimes used for modeling semi-infinite half-spaces are not allowed. For the novice FEA operator, this is not a bad thing because some types of boundary condition specifications require significant understanding of the finite element method in order to successfully formulate a correct problem definition.

The constitutive model used for the base version of the FEA is basically small strain linear elastic isotropic for statics problems. Again, this is not a bad limitation for the novice. The more advanced user can sometimes dance around more complex constitutive models by running multiple analyses with different material properties (e.g. to simulate rheology) and then recombine the results (perhaps with a grain of salt).

The third limitation involves mesh generation and evaluation. The baseline version only has stress analysis. So traction boundary conditions are possible, but specified displacements cannot be applied and probing individual element nodes is not allowed. Even though it is a basic stress analysis package only, the deformed shape is presented, color coded and assigned colors by magnitude of deformation. Therefore, one can obtain a rough idea of where the maximum deformation occurs in the part and the magnitude of that deformation under the assumed boundary conditions and load. Factor of safety is also provided as part of the analysis. Figures 6 
(sharp corner) and 7 (fillet) illustrate the results of FEA performed on the part in Figure 5. In both cases, the load on the rounded end of the arm was $0.7 \mathrm{lbf}$, and the horizontal flat surface along the top of the part was fixed. The materials and other geometric dimensions were the same. In normal use, such an arm might be better modeled by a displacement applied to the curved end of the arm, but if the design is for a dropped condition in which the batteries apply a force to the compartment door when it hits the floor, a force might be more appropriate. Three items from these plots should be of interest to a product designer: (1) the maximum stress in the part is higher in the sharp corner design (Fig 6a vs 7a), (2) the minimum factor of safety is less than 1.0 for the sharp corner design but greater than 1.0 for the fillet design (Fig $6 \mathrm{~b} v s 7 \mathrm{~b}$ ), and (3) the maximum deflection is greater in the sharp corner design (Fig 6c $v s 7 \mathrm{c}$ ). If the material is changed from this generic L/MDPE to the acetal Delrin in the part with the fillet, the maximum von Mises stress stays about the same at 1249 psi, but the minimum factor of safety mushrooms to 7.3 and the maximum displacement shrinks an order of magnitude to $0.003 \mathrm{in}$. The implications for the designer with this change in the material are that a drop may not pop the battery compartment cover open (but normal battery change operations may become a little more difficult for the consumer), the part is unlikely to break at this stress level under normal wear and tear, and different production methods may be required.

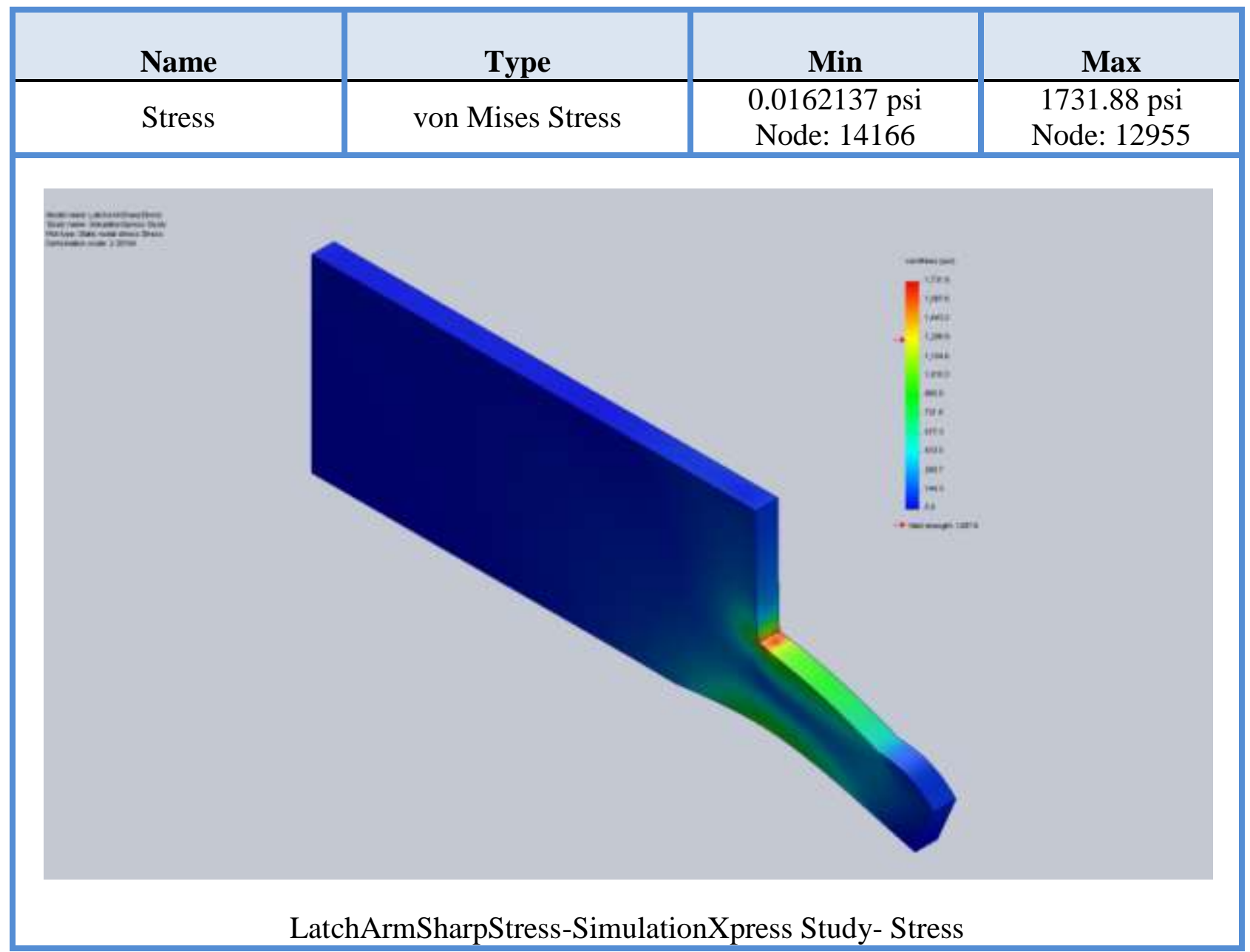

Fig 6a 


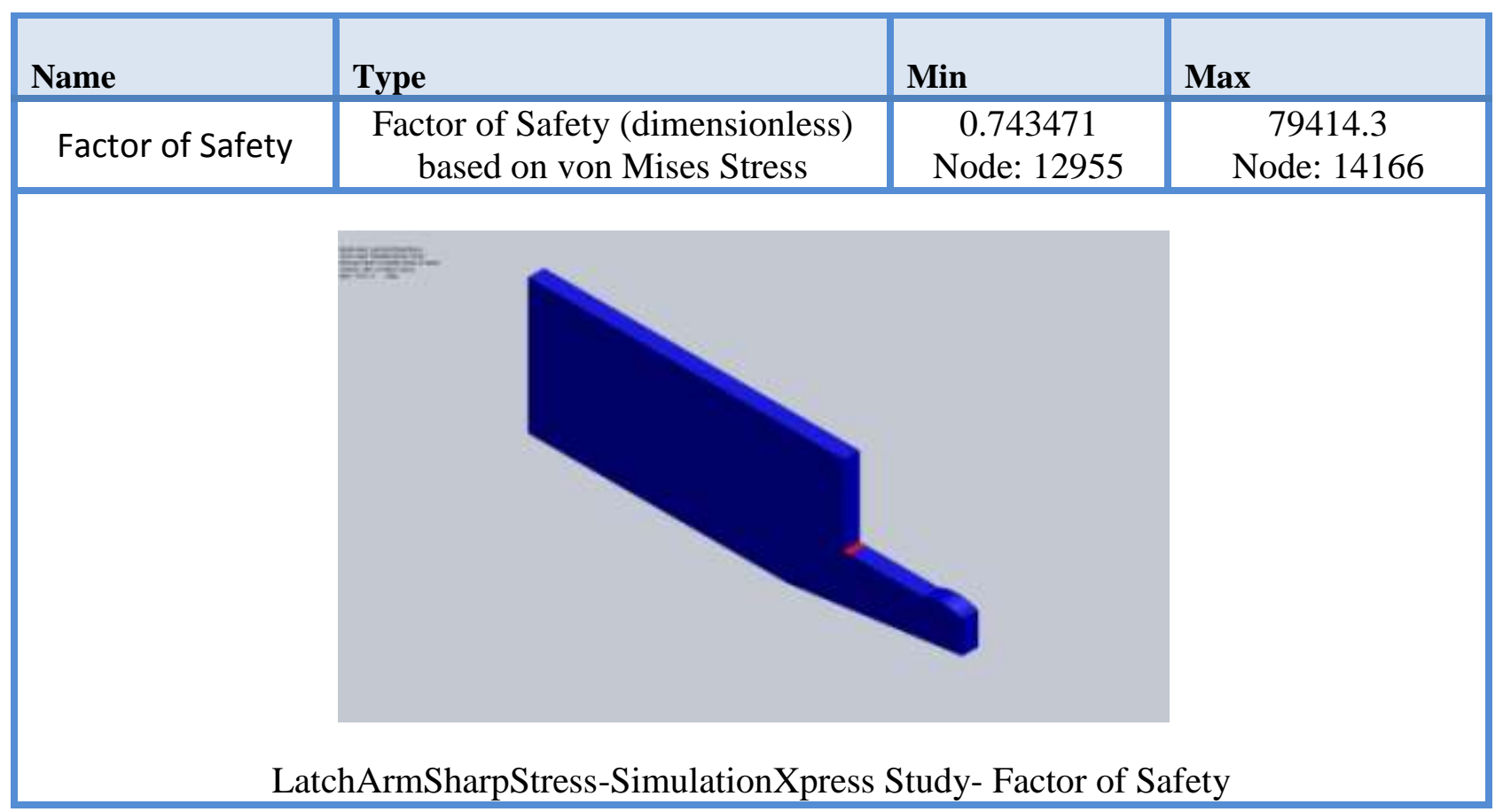

Fig $6 \mathrm{~b}$ (above), 6c (below)

\begin{tabular}{|c|c|c|c|}
\hline Name & Type & Min & Max \\
\hline Displacement & $\begin{array}{l}\text { URES: Resultant } \\
\text { Displacement }\end{array}$ & $\begin{array}{c}0 \text { in } \\
\text { Node: } 1\end{array}$ & $\begin{array}{l}0.0607144 \text { in } \\
\text { Node: } 323\end{array}$ \\
\hline \multirow{5}{*}{ EFi= } & & & \\
\hline & & & \\
\hline & & & \\
\hline & & & \\
\hline & & & \\
\hline \multicolumn{4}{|c|}{ LatchArmSharpStress-SimulationXpress Study- Displacement } \\
\hline
\end{tabular}

Figure 6. Deformation of latch arm with sharp corner (Note: factor of safety less than 1.0 in $6 \mathrm{~b}$ ). 


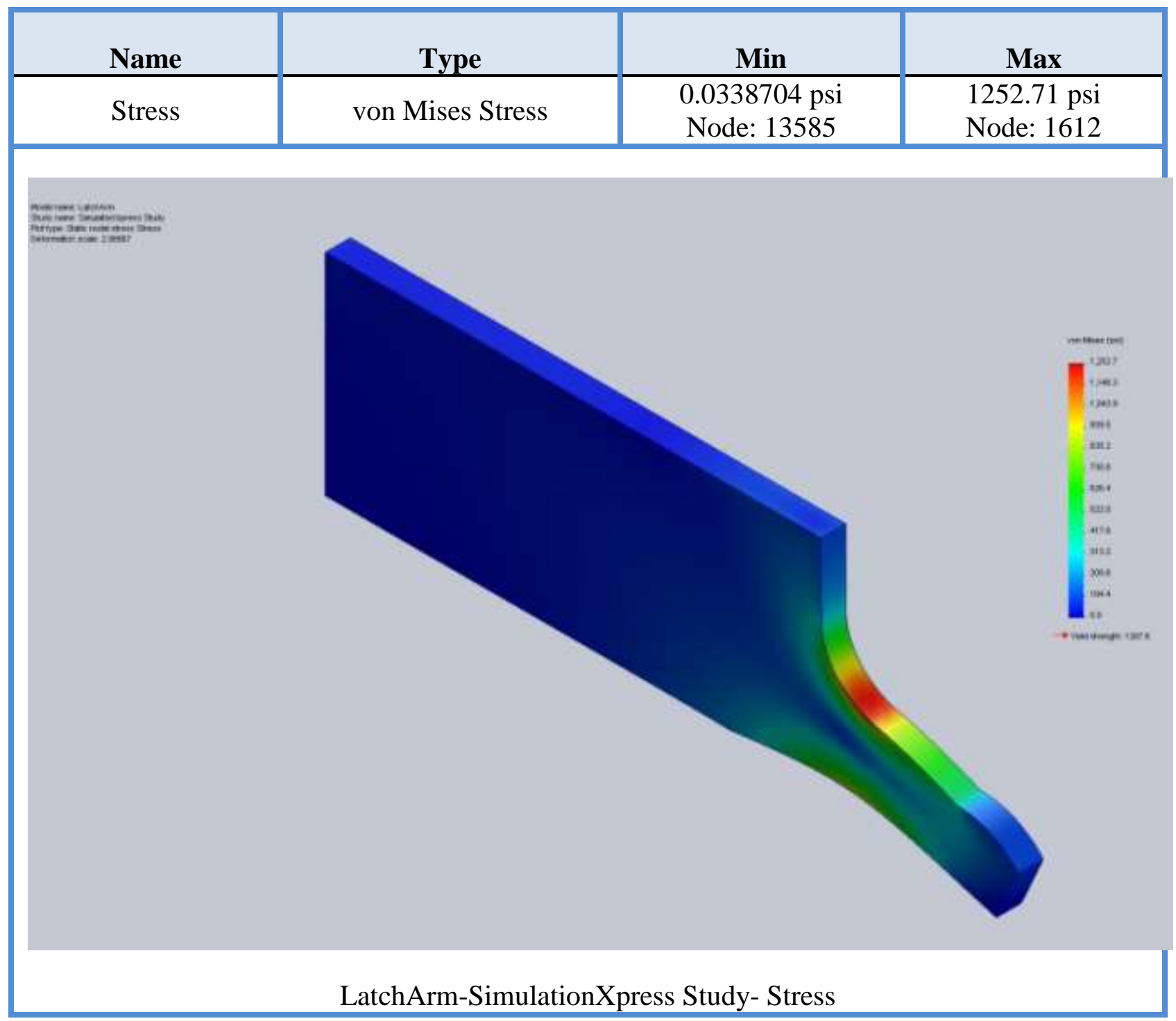

Fig 7a

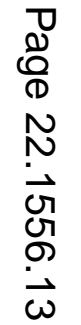




\begin{tabular}{|c|c|c|c|}
\hline Name & Type & Min & Max \\
\hline Factor of Safety & $\begin{array}{c}\text { Factor of Safety (dimensionless) } \\
\text { based on von Mises Stress }\end{array}$ & $\begin{array}{c}1.02785 \\
\text { Node: } 1612\end{array}$ & $\begin{array}{c}38015.5 \\
\text { Node: } 13585\end{array}$ \\
\hline & Ex=- & & \\
\hline \multicolumn{4}{|c|}{ LatchArm-SimulationXpress Study- Factor of Safety } \\
\hline
\end{tabular}

Fig $7 \mathrm{~b}$ (above), 7c (below)

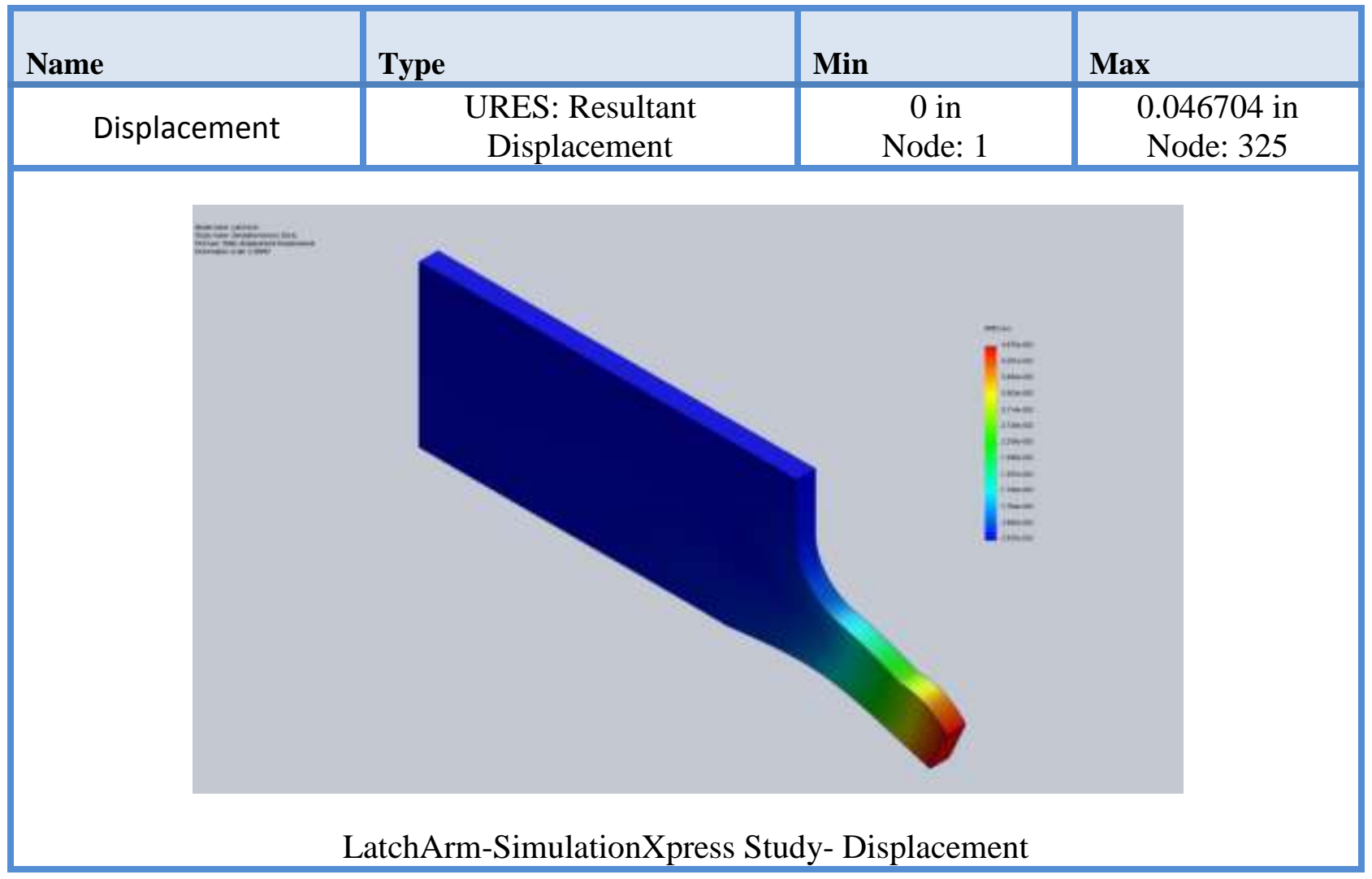

Figure 7. Deformation of latch arm with fillet (Note: factor of safety is never less than 1.0 in $7 \mathrm{~b}$ ).

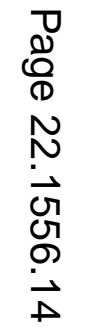




\section{Manufacturing Enhancement - Lean and Automation}

Lean Manufacturing (and "Six Sigma" and several other "buzzwords") is not a panacea for all that ails manufacturing, but it can go a long way toward improving competitiveness and safety. We treat automation in a cursory manner during the course, discussing it where it comes up, primarily in small and medium sized businesses (e.g. bar feeders and pallet loaders). However, $\mathrm{CNC}$ operations are discussed throughout the course, and we spend some time on the implications (including revenue premium, production cost, and capital equipment investment) of designs that require multi-axis machining available with machines such as 5 axis machining centers. While some do not consider CNC to be automation per se because they reserve the term to refer to more complex equipment such as assembly robots, we consider CNC to be a key form of automation that will be present even in small shops. While lean manufacturing embraces automation, it is not an end in itself. Central tenets of lean manufacturing include not only the elimination of waste, but also effective use of people, equipment and physical plant. These tenets are sometimes easier to address in large corporations that have significant depth of staff, but they can be even more important to the smaller "mom and pop" and mid-sized sorts of small businesses that students may find themselves in right after graduation. Carrying the concept to the extreme, the recent graduate with an entrepreneurial spirit and some degree of capitalization may find it useful, and possibly essential, to implement lean concepts in more facets of a startup business than simply manufacturing. Notice that effective use of people is included in the central tenets. A long term error inherent in exportation of manufacturing capability in the sole interest of profit maximization is that ineffective use of the workforce can become crippling to society on a national, if not continental, scale. Guess what, we are there, and those of us in manufacturing who saw it coming years, and even decades ago, now have a chance to say "I told you so". An "information society" will never fully replace the production of "widgets" and food. This fundamental truth is now becoming painfully obvious to even the most casual observer. Our student population may be somewhat demographically unique, but it was interesting and refreshing to see that the students, in this course at least, entered the course with a somewhat surprising understanding of the implications of this manufacturing base exportation, not only from a workforce perspective, but also from a national security perspective. We suspect this understanding, coupled with an inherent competitive entrepreneurial spirit and more "hands on" learning mentality of our students, in part drove the enthusiasm of the students for their projects. One can make an argument that the sole purpose of a corporation is to maximize profits for the shareholders, but this can be a pretty short-sighted interpretation.

In the course, we cover most lean concepts as applied to manufacturing in particular, with the intent to eliminate waste in small OEM (original equipment manufacturer) and job shop manufacturing settings, so that these entities can successfully compete and become responsible corporate and individual citizens in the event that the playing field ever becomes level (or at least tilted only slightly uphill). Because we intend other courses to cover topics such as CNC machining in detail, we focus on two areas related to manufacturing in this course: (1) lean concepts, and (2) design conversion to what might be referred to as "additive CAM". Solid modeling is used with either Autodesk Inventor or SolidWorks solid models to produce physical prototypes on a Stratasys 3D printer. While this eliminates the need to go through the additional steps of fixturing, tool selection and tool changing plans, and $\mathrm{G}$ code generation typically required for $\mathrm{CNC}$ machining centers, it still provides the student with an understanding of how one can go from the proverbial "drawing on a napkin", to a solid computer model, to a physical 
prototype or even a finished product. There seems to be no real suitable replacement for the enthusiasm that a physical prototype can generate. More than one of the physical prototypes produced in this course made it back to the student's parents and family for "show-and-tell".

Figure 3 gives a timeline and shows the basic lean manufacturing subject areas that are treated in the first part of the course. Concepts such as 5S, kanban, and error proofing are covered with the aid of SME (Society of Manufacturing Engineers) Manufacturing Insights video products to bring home real world examples of how lean concepts are applied in industry. The video products were well-received by the students. A field trip for a plant tour of a manufacturing firm using SolidWorks for designing large oilfield related equipment put the icing on the cake. This company designs, produces, and tests very complex and large equipment at one location comprising several indoor and outdoor facilities. Seeing the integration of design, manufacturing and what was lean and not so lean in a production manufacturing facility was also received well by the students.

By the time of the field trip and production of the physical prototypes, the students had been exposed to the basic lean body of knowledge. One component of that body was value stream mapping (VSM). Sufficient time was not available to run multiple scenarios and cover every component of VSM in detail, so even though complete current and future state maps were presented, focus was placed on specific areas related to production lead time, including concepts such as takt, cycle, changeover, and setup times, 5S, kanban, supermarket, pull, and manufacturing cells, all topics that had been covered prior to the VSM exercises (VSM was introduced early, then exercised in more detail later after relevant topics had been covered). The focal area of the VSM was more "tactical" in nature and is illustrated in Figure 8. In the measurement exercises associated with lean manufacturing, more quantitative concepts were tested than might be seen in some of the measurements of the kernel topics. It was found in measurement exercises for this section of the course that the matching format of questions with more options than required for 1:1 correspondence, and simple mathematical computations such takt time with "givens" that had more information than was necessary to solve the problem, generated stumbling blocks for some students. Therefore, understanding of some of these concepts was reinforced by reappearance of these topics on additional measurement exercises. For example, correct computation of takt time on a problem for which the given data included data for both takt time and pitch was achieved by a few students on the first measurement exercise, by most students on the second measurement exercise in which a similar problem appeared, and by almost all students by the time a similar problem appeared on the comprehensive final. 


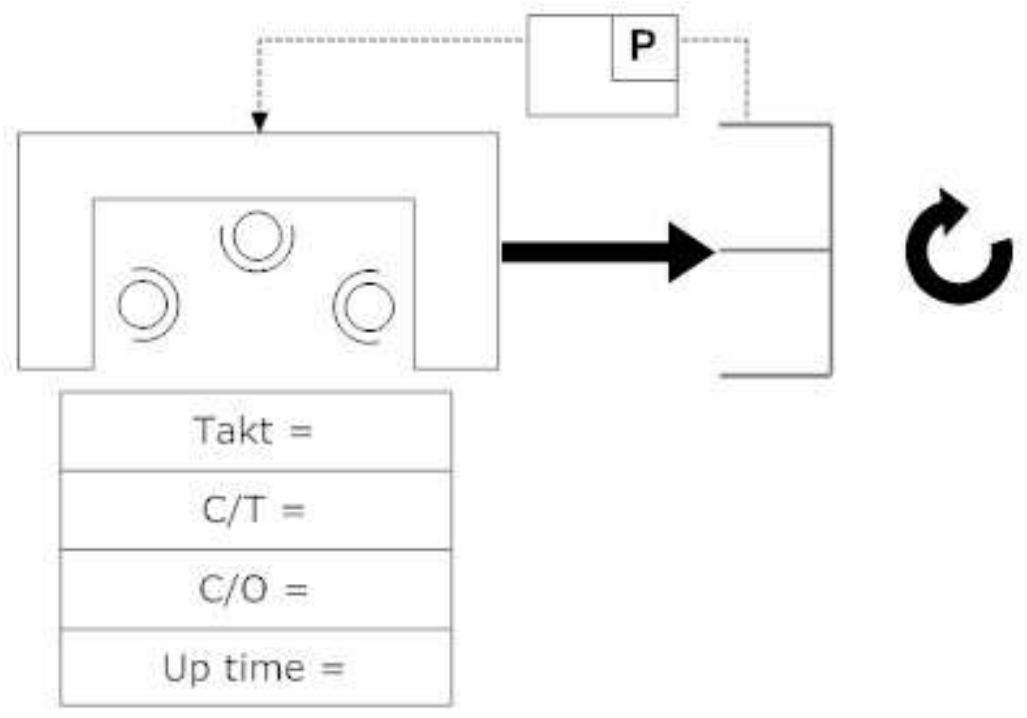

days

$\min$.

Figure 8. Focal area of the value stream map for "tactical" applications.

\section{The Design Project - Philosophy and Measurement}

Ulrich and Eppinger ${ }^{10}$ provide valuable discussion of considerations related to the design project(s). In particular, three items are related to this paper: (1) methods of generating project ideas, (2) general project guidelines, and (3) measurement of project assignments.

Methods of generating projects suggested by Ulrich and Eppinger ${ }^{10}$ include: (a) studentconceived projects, (b) industry-sponsored projects, and (c) faculty-specified projects. They also provide advice on general project guidelines, one of which we approached more like a challenge instead of advice: "Save any highly proprietary ideas for another context; we will be quite open in discussing the projects in class and do not wish to be constrained with sensitive information." ${ }^{, 10}$. Deviating from this piece of advice may not be for the faint of heart, but we charged in anyway. There is a method behind the madness however. It is tied to the methods of generating project ideas. We did not have any industry-sponsored project opportunities, and the intellectual property section of this paper does not cover that option, so our methods were limited to (a) and (c) above. Early in the semester, the first author polled the students as to which option (student-conceived, or faculty-specified) they would prefer for the major project assignment. The students unanimously elected to use student-conceived projects, and student formed groups. We allowed a single student to constitute a "group", with the result that groups ranging from 1 to 3 members were formed. Further, the students unanimously reported that they would reveal proprietary/patentable content during their project presentation. Our objective was to be open in discussing the projects in class AND not be constrained in the discussions. The level of interest shown by students involved in their design projects was, at least in the opinion of the primary 
author, much higher when they were allowed to select their own project rather than being assigned one by the instructor. The approach virtually ensures that the following guideline comment becomes reality: "The most successful projects tend to have at least one team member with strong personal interest in the target market"10. Fostering this entrepreneurial spirit was one of the objectives of the course. In the opinion of the first author (a holder of utility patents as sole inventor), of the initial 9 proposed projects, 3 appeared on cursory inspection to have some utility patent potential with reasonably broad claims possible, and the rest either might have been utility with very limited protection or more likely design patents or not patentable.

Unfortunately, one of the high potential projects was not completed because the student could not continue with school that semester, and another of the high potential projects turned out to be too large of an effort to complete during the semester and that student decided to move onto one of the design patent type projects a few weeks before the final project was due. Cost and complexity guidelines had been discussed at the outset, so this latter student was given a suggested scope that could have been accomplished within the timeframe, but although he had an idea, he did not have the background to carry through with the project. All factors considered, there was a reasonable showing of originality on the part of the students on each project, and all showed enthusiasm for their projects.

At the time a non-disclosure agreement (NDA) was needed for this course, the primary and secondary authors did not know each other, so the primary author modified a basic NDA from Nolo Press ${ }^{11}$ to use for the course. The NDA shown in Appendix A and the discussion in the intellectual property section of this paper presented by the second author constitute a more robust instrument than that prepared on the first cycle by the first author, and this new version will be used in the future. In the first cycle of the NDA approach, there was no hesitation by any student concerning signing the NDA. It remains to be seen if there will be resistance to signing the new version since it is a bit more rigorous. A "bare bones" short form version of the NDA is provided in Appendix B. As was the case during the first cycle, there will be no pressure put on the students to sign the NDA in future cycles. The options will be presented at the start of the course as follows:

1. Everyone in the class (including the instructor) complies with, and signs, the NDA, or

2. Student-conceived projects must not include intellectual property unless the disclosing student is willing to risk loss of protection rights and/or is willing to start the US one year time clock and lose international rights, or

3. The instructor will assign projects.

In the next section on intellectual property, it is useful to keep in mind that there are actually two purposes to the NDA, one of which is instructional and one of which is legal. The legal objective is to help students protect their ideas while simultaneously obtaining academic credit for doing useful and productive work on a subject about which they are excited. The instructional objective is to introduce the student to the type of instrument typically used by businesses for which they might work when they graduate. Terms of employment often contain NDA type documents that amount to automatic assignment of patents to the corporation in return for the employee's salary, and actually signing such a document, instead of simply reading about it, changes the experience from a passive academic exercise to something more significant.

On the subject of measurement, Ulrich and Eppinger provide the following discussion: 


\begin{abstract}
"We also like to photocopy the best assignment handed in each week and distribute a copy to each team. This creates a bit of competition and allows the entire class to share their experiences. We grade the weekly assignments on a scale of 0 to 10 . We don't give grades of 0 through 4 (part of the psychology of grading). A 7.5 is defined as "meeting our expectations for the assignment." A 10 corresponds to an excellent job by a professional team. We give few 10s, and seem to give an average grade of about 8.5. In our experience, grading the course as a whole is quite difficult. The problem is that teamwork reduces the variance in grades." 10 (Note: bold emphasis added)
\end{abstract}

We fully agree with the authors of the text that grading the course as a whole is quite difficult. There are many qualitative and "fuzzy" concepts in this type of course, and team project(s) tend to amplify some of the less quantitative features of the endeavor. Group efforts in the classroom are sometimes problematic because the tendency is for a few members of the group to do all the work and the others to skate by. This approach does not work for very long once the student has entered the workforce because small business relies on everyone pulling their weight and those who do not sometimes experience short tenures with the company. But in the classroom, the stakes are not as high and the skating is not as obvious unless specific measures are taken to expose it. One method of addressing the issue of variance reduction due to group evaluation in this type of projects course is well treated by Earle and Wood ${ }^{12}$. To determine individual grades from group efforts, they use a nomograph in conjunction with (a) student assigned values of percent contribution for each member of their own group, and (b) an overall team grade assigned by the instructor. This assumes, of course, that the students provide an honest assessment of their peers, and on the whole this would seem to be a reasonable assumption if it is done "in the blind". To evaluate the initial project proposals, we used a similar concept but did not use the same approach. We had the students rank the project proposal presentations and the instructor provided his own ranking and grade for each. The students' rankings were converted to grades. Since each individual was required to present on the project proposal, this procedure resulted in two grades for each student on a single proposal delivered by the student. Since each individual was evaluated, there should be less of a tendency to compress the variance due to the "team" evaluation phenomenon (although variance compression can still occur if the presentations are of comparable quality, but the use of "ranking" instead of "grading" per se would seem to tend to mitigate the phenomenon, depending upon how the conversion from ranking to grading is done while considering quality and desired completion standards).

This idea was expanded in a different way for the final project presentations so that the direct student input to the grade was eliminated and all grading was done by the instructor. In our course, group sizes ranged from 1 to 3 students. So, we were presented with the question of how to generate the same level of effort for each student and simultaneously reduce the tendency to compress the sample variance. The level of effort for each group was tied to the number of members of the group. A baseline requirement was established for a group size of one individual, and additional requirements were specified for larger groups. Since the maximum group size included 3 members, a selection of requirements was presented upon which individual members could choose to concentrate (e.g. one member could do a patent search and write the patent, one could do a marketing, business or manufacturing plan, one could work on a physical prototype, etc.). Every group, regardless of size, was required to meet a minimum baseline. The baseline required that (1) a presentation would be delivered by each team member on a different 
topic within the project, and (2) a written document in the form of a patent would be presented by the team for the product that was the subject of the project (this was required regardless of whether the product was actually patentable or not). For example, a "group" comprising only one individual was required to prepare a draft patent on their product, and do a presentation. Individuals who had products that could be run through our 3D printer generally elected to do a presentation using the patent as background and the physical prototype as a "show-and-tell" focus for discussion. Single person "groups" that could not produce a physical prototype due to the nature (usually size) of their product typically used solid modeling software to present a "show-and-tell" focal point. For groups with multiple members, one member would typically do what a single member "group" would do, and the other members would develop and present another facet of the product such as a manufacturing plan. While this approach may not totally even out the level of effort since single person "groups" might still expend more effort than some members of larger groups, it did tend to level the playing field somewhat more than if no additional requirements had been placed on the larger groups.

Instead of simply assigning a single grade to each person, three grades were assigned to each person: (1) a group measurement, (2) an evaluation of the written patent, and (3) a presentation measurement (which had the dual effect of measuring the individual's presentation skills as well as individual technical content). Because the patent document was considered a product of the group, both the overall group measurements and the patent evaluations were assigned to each member of the group, but the presentation measurements were direct consequences of each individual's effort. The results of this measurement exercise were that the lowest mean and median component of the measurement was the presentation. The presentation also had the largest sample variance at approximately 77. The patent document evaluation and the overall group measurement had sample variances of approximately 20 and 38, respectively (all variances computed in Excel using equal counts). All three evaluations were assigned independently (e.g. the overall group measure was not mathematically derived from the other measures, but was assigned independently by the instructor). The lower variance for the patent document evaluations may have been in part due to the way the count was handled, but it was also due to the fact that the documents started from the same format and similar content (students were advised to find a related patent using www.uspto.gov and base their patent on that format), and seemed to reach a similar level of quality within the project timeline. An objective for the next cycle of the course is to increase the quality of both the patent documents and the presentation skills. It is uncertain whether meeting that objective will tend to decrease or increase the variance within those two components of the projects.

\section{Intellectual Property - Challenges of Developing Inventions in a Classroom Setting}

Attempting to develop patentable products cooperatively in a classroom setting raises three salient legal issues: (1) joint inventorship, (2) possible statutory bar to patentability resulting from an in class publication leaking out to the public and (3) the issue of whether sufficient consideration exists to support an enforceable contract.

A. A Critiquing Student May Become a Joint Inventor if He or She Conceives of Something that Ultimately Becomes Part of a Claim in the Presenting Student's Patent Application 
The issue of joint inventorship can arise because one student may make a suggestion for improvement of another student's invention and that suggestion may ultimately become incorporated into that invention. In such a case, the student who suggested the improvement may have become a joint inventor of the ultimate product.

The United States, unlike many other countries, requires that patent applications be prosecuted and issued in the name of the true inventor(s); failure to do this will render a U.S. patent invalid.

The law of joint inventorship for purposes of U.S. Patents can be found at 35 U.S.C. $\S \S 116 \&$ 120 and Manual of Patent Examining Procedure \$2137.01. 35 U.S.C. $\$ 116$ provides, in pertinent part, as follows:

\section{$\S 116$. Inventors}

When an invention is made by two or more persons jointly, they shall apply for patent jointly and each make the required oath, except as otherwise provided in this title. Inventors may apply for a patent jointly even though (1) they did not physically work together or at the same time, (2) each did not make the same type or amount of contribution, or (3) each did not make a contribution to the subject matter of every claim of the patent.

If a joint inventor refuses to join in an application for patent or cannot be found or reached after diligent effort, the application may be made by the other inventor on behalf of himself and the omitted inventor. . . .

This statute has been judicially interpreted to mean that joint inventorship requires that two or more persons jointly contribute to the conception of an invention. Fina Oil \& Chemical Co. v. Ewen, 123 F.3d 1466, 1473 (Fed. Cir. 1997). However, "[T]he determination of whether a person is a joint inventor is fact specific, and no bright-line standard will suffice in every case." $I d$. The difficulty in determining exactly who is and is not a joint inventor has long been noted by U.S. courts: "the exact parameters of what constitutes joint inventors are quite difficult to define. It is one of the muddiest concepts in the muddy metaphysics of the patent law." Mueller Brass Co. v. Reading Industries, 352 F. Supp. 1357 (E. D. Pa. 1972).

The best that can be done in a typical classroom setting to alleviate the legal problem of who is and is not a joint inventor is to make sure that each of the students in a particular class chooses an invention to work on that is conceptually completely distinct from the inventions being worked on by each of the other students and to require that each student write up a detailed report of the suggestions and criticisms of his or her invention that are made by other students in the class and clearly identify which student made which suggestions and criticisms.

Doing these two things will reduce the likelihood of joint inventorship and, should joint inventorship occur, will make it easier to identify who the joint inventors are and what aspects of the invention they are joint inventors of. 
B. If a Presenting Student's Classroom Presentation Becomes Available to the Public, the Student Must File for a U.S. Patent within One Year in Order to Avoid a Statutory Bar and Usually Will Be Disqualified from Patent Protection Under the Laws of Other Countries.

Virtually all countries other than the United States have a first-to-file system of priority that encourages a rush to their respective patent offices. If an act that would disqualify an invention from a patent, such as a publication, occurs prior to filing in first-to-file countries, the patent application may be denied.

The United States, by contrast, follows a first-to-invent system and provides a one year grace period to file after the occurrence of certain patent disqualifying events. 35 U.S.C. $\$ 102$ sets forth two different types of statutory bar events: those that are universal (apply to events both in the U.S. and in foreign countries) and U.S. restrictions (which apply only to events in the U.S., but which do not apply to events that happen in foreign countries).

A "plain language" version of 35 U.S.C. \$102(b) could be written as follows, without changing the meaning of the actual current statutory language:

Any of the following events will bar a U.S. patent from issuing if such event occurs more than one year prior to the date that the U.S. patent application is filed with the U.S. Patent and Trademark Office:

(1) Universal Statutory Bar Events. The invention was, either in the U.S. or in a foreign country: (a) patented or (b) described in a printed publication.

(2) U.S. Statutory Bar Events. The invention was, in the U.S.: (a) in public use or (b) on sale.

U.S. Courts have looked to the degree of public accessibility and dissemination of information when determining whether a prior printed publication has occurred under 35 U.S.C. Sec. 102(b). In re Klopfenstein, 380 F.3d 1345, 1348 (Fed. Cir. 2004) reh. den., en banc den. (Fed. Cir. 2004). Specifically, courts have recognized that they will take cognizance of whether protective measures have been used to limit public accessibility to and dissemination of information, such as non-disclosure agreements. Id., 380 F.3d at 1351.

The holding of In re Klopfenstein was subsequently expanded to state that static presentation of slides can serve as a substitute for paper, although a video cannot. Diomed, Inc. $v$. AngioDynamics, Inc., 450 F. Supp. 2d 130, 141-42 (D. Mass. 2006). Therefore, it would appear that even a PowerPoint presentation to a class could constitute a "printed publication" that will trigger the time limitations of 35 U.S.C. Sec. 102(b). The implication of this case is that students should be encouraged to use videos to present their inventions to the class rather than PowerPoint presentations, slides or printed material.

Another U.S. court was willing to hold that posting information on the World Wide Web constituted a "printed publication" within the meaning of 35 U.S.C. Sec. 102(b), although this holding was overturned on appeal based on other grounds than the Court's construction of 35 U.S.C. Sec. 102(b). Dow Jones \& Co. v. Ablaise Ltd., 632 F. Supp 2d 23, 37 (D. D.C. 2009) 
rev'd in part on other grounds, Dow Jones \& Co. v. Ablaise Ltd., 606 F.3d 1338 (Fed. Cir. 2010). A non-disclosure agreement for a class should therefore bar dissemination of such information over the Internet.

Information regarding student inventions also needs to stay in the class itself and to be withheld from the university at large, since at least two cases have held that making a student thesis available in a university library is sufficient to trigger the one year bar of 35 U.S.C. Sec. 102(b). See In re Hall, 781 F.2d 897 (Fed. Cir. 1986) and Hamilton Laboratories, Inc. v. Massengill, 111 F.2d 584, 585 (6 ${ }^{\text {th }}$ Cir. 1940), cert. den. 311 U.S. 688 (1940).

\section{C. $\quad$ Consideration or a Consideration Substitute Such as Promissory Estoppel Must Exist to Render the Confidentiality Obligations of the Non-Disclosure Agreement Enforceable}

The common law of contracts in countries whose legal systems are descended from the common law of England provides that "consideration" is a necessary element of a legally enforceable contract in most cases. Jurisdictions that embrace the common law tradition include every state in the United States except Louisiana, as well as almost all of the countries that were formerly part of the British Empire. The roots of the ancient doctrine of consideration hearken back more than two centuries to an English case, Rann v. Hughes, 7 T.R. 350n, 101 Eng. Rep. 1014n (1778).

A typical definition of consideration can be found in the New York case of Hamer v. Sidway, 124 N.Y. 538, 27 N.E. 256 (N.Y. 1891) wherein New York adopted the following definition of consideration from an English court: "A valuable consideration, in the sense of the law, may consist either in some right, interest profit, or benefit accruing to the one party, or some forebearance, detriment, loss, or responsibility given, suffered, or undertaken by the other." Id., 124 N.Y at 545, 27 N.E. at 257.

"Consideration" is, in essence, bargained for legal detriment. This means that the student must legally obligate him or herself to do something that he or she would not otherwise have any legal obligation to do or to refrain from doing something that he or she would otherwise be legally free to do.

The element of consideration can be satisfied in most common law jurisdictions by mutual promises between students to exchange ideas and to keep the idea disclosed confidential. However, while this is sufficient to provide consideration between the disclosing students, what legal consideration would be provided by the instructor and by any non-disclosing students to the students who present their inventions to the class? None.

The instructor's duty to help the students is a pre-existing duty and therefore is not cognizable as consideration and the non-presenting students are not disclosing any ideas. Therefore, there is no consideration sufficient to support a legally enforceable contract, unless the instructor and the students are paid to sign the non-disclosure agreement. However, having everyone pay everyone else for silence is cumbersome in a classroom setting, even though this would probably be done if we were working in the context of private industry. 
The answer to the dilemma of lack of consideration can be found in the legal doctrine of promissory estoppel. The common law of contracts has long recognized that promissory estoppel may serve as a substitute for consideration. Promissory estoppel requires either detrimental reliance on a promise or a change in position based upon a promise. Additionally, courts have imposed the requirement that the reliance on a promise must be reasonable.

We can use the law of promissory estoppel in crafting our non-disclosure agreement to make it enforceable by making a promise of confidentiality in order to induce disclosure of confidential information. In such a case, the disclosing party is changing position and detrimentally relying on the promise of confidentiality. Therefore the doctrine of promissory estoppel can be applied to prevent a signor of the non-disclosure agreement from challenging it on the grounds of lack of consideration.

\section{Conclusion - Coconut or Walnut?}

Is it possible for the new faculty member to crack this nut in one 3 semester hour course? It depends. In our case, we were able to cover the material (admittedly in some cases with more cursory treatment than desired) most likely because of two main factors: (1) the course was listed as a 3 semester hour course but was actually scheduled to meet 3 hours and 40 minutes contact time per week, similar to some laboratory based courses, and (2) we only assigned one major project for the duration of the course, with the remainder of the measurement effort generally resting on quizzes, major exams, homework, and class participation. Based on our experience, if the course were relegated to 3 contact hours per week, we would offload some of the main textbook subjects to student reading assignments outside of class that would be measured on major exams only, and expand the effort in solid modeling, material properties, stress/strain analyses, and $\mathrm{CNC}$ manufacturing. We did not address quantitative fatigue considerations such as S-N curves, fracture toughness and seemingly contraindicated phenomena such as "strengthening" versus "weakening" in ductile versus brittle materials. We intend to address these shortfalls in the next offering only in a qualitative sense, so that the uninitiated students will have something in the back of their minds if they see the problem after graduation or in a detailed course offering on the subject of material behavior later in their degree plan.

We have presented a course timeline and approaches to tweaking product design and development for the purpose of expanding the depth of coverage in the technological component of a broad based course in the field, focusing on three topics: (1) engineering (materials and geometry), (2) manufacturing (processes and efficiency in pre-production and full production applications), and (3) intellectual property (both long and short form versions of the NDA for classroom use are provided in Appendix A and Appendix B, respectively). 


\section{Bibliography}

1. Ulrich K T and Eppinger SD, Product Design and Development, McGraw-Hill, $4^{\text {th }}$ ed., 2008.

2. http://www.ulrich-eppinger.net/instructors/Intro/howto.htm

3. Tapping D, The New Lean Pocket Guide, MCS Media, 2010.

4. Kremer R and Tapping D, The Lean Manufacturing Training Set, MCS Media, 2005.

5. Callister W D and Rethwisch D G, Materials Science and Engineering An Introduction, J. Wiley, $8^{\text {th }}$ ed., 2010.

6. Hertzberg R W, Deformation and Fracture Mechanics of Engineering Materials, J. Wiley, $2^{\text {nd }}$ ed., 1983.

7. Rother M, and Shook J, Learning to See, The Lean Enterprise Institute, Version 1.3, 2003.

8. Young W C and Budynas R G, Roark's Formulas for Stress and Strain, McGraw-Hill, $7^{\text {th }}$ ed., 2002.

9. http://www.matweb.com

10. http://www.ulrich-eppinger.net/instructors/Intro/projects.htm

11. http://www.nolo.com

12. Earle J H and Wood B, Geometry for Engineers 3, Creative Publishing Company, 2004 (1 $11^{\text {th }}$ printing September 2008) 


\section{Appendix A -Non-Disclosure Instrument (Long Form)}

\section{CONFIDENTIALITY, NON-DISCLOSURE AND \\ DEVELOPMENT AGREEMENT}

THIS CONFIDENTIALITY, NON-DISCLOSURE AND DEVELOPMENT AGREEMENT ("Agreement") is made and entered into this day of 20 (the "Effective Date") by and between all of the students and instructor(s) in the Class as set forth in Exhibit A to this Agreement (collectively, "Class Members").

WHEREAS, the Class Members promise to each other that they will keep confidential any inventions that are divulged to them by other Class Members, and

WHEREAS, in reliance upon this promise of confidentiality, Class Members are prepared to disclose to each other inventions and concepts that they otherwise have no duty to disclose, and

WHEREAS, it is a purpose of the Class to develop potentially patentable and commercially exploitable inventions, and

WHEREAS, it is also a purpose of the Class to have students gain consulting experience by critiquing each others' inventions and suggesting possible improvements or other ideas relating to each other's inventions,

NOW, THEREFORE, in consideration of the mutual promises, covenants and representations contained herein and other good and valuable consideration, the receipt and sufficiency of which are hereby acknowledged, the Class Members hereby covenant and agree as follows:

a) Consulting Engagement. Subject to the terms and conditions set forth herein, each student Class Member hereby agrees to work as a consultant for one semester on a barter basis to critique and suggest possible improvements or other ideas relating to any inventions that may be presented to the Class by any other members of the Class. All work done during this semester by any Class Member on any other Class Member's invention shall be known as the "Consulting Engagement". The Consulting Engagement shall terminate when the semester specified in Exhibit A shall end.

b) Duties of Class Members. A Class Member may to disclose to the Class information relating to his or her invention for the sole purpose of allowing the other student Class Members to perform their consulting duties under this Agreement. Each Class Member who discloses information relating to his or her invention to other Class Members shall be called a Disclosing Class Member. Class Members who are not students shall be obligated to facilitate discussion among the student Class Members in accordance with university policy. 
3. Duty to Keep Proprietary Information Confidential. During the term of the Consulting Engagement and at all times after the termination of the Consulting Engagement, Class Members shall not use, directly or indirectly, and shall hold in strict confidence and refrain from disclosing to others, except to other Class Members for the benefit of the Disclosing Class Member, the Confidential Information of the Disclosing Class Member.

a. "Confidential Information" shall be deemed to include, but shall not be limited to, specifications, drawings, models, pictures, videos and PowerPoint presentations depicting part or all of the Disclosing Class Member's invention, trade secrets, data, products, operational methods, technical processes, techniques, information, source codes, object codes, executables, software, and/or any other information of the Disclosing Class Member or which the Disclosing Class Member uses or may use in practicing the Disclosing Class Member's invention, but shall exclude information which:

(1) was already known to the other Class Members prior to this Agreement;

(2) becomes generally available to the public other than through a breach of this Agreement;

(3) is furnished to the other Class Members by a third party who is lawfully in possession of such information and who lawfully conveys that information; or

(4) is required to be disclosed by law, court order or other legal means.

b. Class Members shall not post any Confidential Information on any Internet web site, social networking site (including, but not limited to, Facebook and My Space) or disseminate Confidential Information outside the Class via text message, e-mail, cell phone photo, photocopy or by any other means whatsoever.

c. In the event the Consulting Engagement terminates for any reason whatsoever and at the end of the current semester, Class Members shall return to the Disclosing Class Member originals and copies of any and all Confidential Information or shall immediately permanently destroy same and shall provide certification of the destruction to the Disclosing Class Member upon demand. Class Members acknowledge and agree that the memorization or mental retention of the Confidential Information shall be subject to the restrictions contained in this Agreement.

d. Class Members further agree that the definition of the term "Confidential Information" and the restrictions on its use as contained herein are fair and reasonable.

4. Disclosing Class Member's Property. All Confidential Information, intellectual property, copyright material and/or other documents, instruments and property (either tangible or intangible) made, conceived, compiled, obtained or acquired by any Class Member, on behalf of the Disclosing Class Member, during the period of the Disclosing Class Member's relationship with the Class, whether confidential or not, are the property of the Disclosing Class Member and shall promptly be delivered to the Disclosing Class Member upon the earlier of the termination of this Agreement or the end of the semester. 
a. Nothing in this Agreement shall be construed to grant to Class Members any license or other rights in or to the Confidential Information of the Disclosing Class Member.

5. The Disclosing Class Member's Right to Discoveries. The Class Members agree that all of the Class Members' work-product on the invention of the Disclosing Class Member is the result of work for hire and, as such, all discoveries, inventions, improvements, formulae, software, source codes, object codes, ideas, devices, writings or other intellectual property, whether or not subject to patent or copyright laws, which Class Members shall make or conceive solely or jointly with others in the course or scope of the Consulting Engagement, or with the Disclosing Class Member's materials or facilities, and including all work-product with the look, feel and touch of any program invented by the Disclosing Class Member, shall be the sole and exclusive property of the Disclosing Class Member without further compensation.

a. Any invention or work-product, based upon the Disclosing Class Member's Confidential Information, or with the look, feel and touch of any program invented by the Disclosing Class Member, occurring anytime after termination of the Consulting Engagement shall be deemed to be the sole property of the Disclosing Class Member.

b. Class Members shall assign to the Disclosing Class Member or to the Disclosing Class Member's designees, any patent application made by any Class Member that is derived from, or conceived or made using, the Disclosing Class Member's invention or Confidential Information.

c. Each Class Member shall, at the Disclosing Class Member's request and sole expense, make necessary application for domestic or foreign patents based on the Disclosing Class Member's invention or Confidential Information and shall assist in securing, defending or enforcing any such title and right thereto, and assist in any other litigation concerning the Disclosing Class Member, the Confidential Information and any invention of the Disclosing Class Member that was developed in connection with the Class.

d. Class Members shall assign to the Disclosing Class Member or to Disclosing Class Member's designees, the entire right, title and interest in all properties conceived or made at any time during or after the Consulting Engagement by Class Members to the extent that such right title and interest was derived, directly or indirectly, from the Disclosing Class Member's invention or Confidential Information.

\section{6. $\quad$ Remedies and Enforcement.}

(a) Each Class Member understands and acknowledges that in the event that any provision of this Agreement is breached, the Disclosing Class Member will suffer irreparable damage for which money damages do not provide an adequate remedy. Therefore, Class Members agree that should any Class Members violate any of the terms hereof, the Disclosing Class Member may obtain an injunction without bond, restraining any breaching Class Members from participating in the violative activity pending the 
determination of the controversy between the Disclosing Class Member and Class Members in a court of law.

(b) The equitable remedies available to the Disclosing Class Member pursuant to this Agreement are not exclusive and the remedies of the Disclosing Class Member in equity are in addition to all other remedies, including an action for damages, which the Disclosing Class Member may have by reason of Class Members violating any of the provisions of this Agreement.

(c) If any of the provisions of this Agreement shall be adjudicated by a court of law to be partially or totally invalid or unenforceable, the invalid provision shall be deemed modified to the extent necessary to render it valid and enforceable, or shall be excised from this Agreement, as circumstances may require, and this Agreement, subject to such modification or deletion, shall be enforced to the maximum extent and scope permitted by law.

(d) The failure to enforce at any time any of the provisions of this Agreement or to require at any time performance by any party of any of the provisions hereof shall in no way be construed to be a waiver of such provisions or to affect the validity of this Agreement, or any party hereof, or the right of any party thereafter to enforce each and every such provision in accordance with the terms of this Agreement.

7. Attorneys' Fees. Class Members recognize and understand that if this Agreement is breached by Class Members or if the Disclosing Class Member must take action to enforce this Agreement against Class Members, then such actions will be extremely inconvenient and costly for the Disclosing Class Member. The prevailing party in any litigation or other proceeding relating to this Agreement between the Disclosing Class Member and any Class Member shall therefore be entitled to recover all costs, expenses and reasonable attorneys' fees incurred.

8. Assignment. This Agreement may not be assigned by any party hereto, in whole or in part, without the prior written consent of the other party; provided, however, that any assignee of any party may further assign this Agreement, without any other party's consent, to a third party pursuant to a merger, consolidation or as the result of the sale or transfer of all or substantially all of the assets or equity interests of the assigning party. This Agreement shall be binding upon and shall inure to the benefit of the parties, their respective successors and permitted assigns.

9. Applicable Law. This Agreement shall be governed by, and interpreted in accordance with, the laws of the State of Texas without regard to its conflicts of laws provisions.

10. Inconsistent Obligations. Each Class Member agrees that he or she has not accepted, nor shall assume during the Consulting Engagement with the Disclosing Class Member, any obligation that is or will be inconsistent with those in this Agreement.

11. Modification. This Agreement shall not be changed or modified except by written instrument signed by the party to be charged with the modification. 
12. Counterparts. This Agreement may be executed in any number of multiple counterparts with the same effect as if the signatures thereto and hereto were upon the same instrument. Each such counterpart shall be deemed an original, but all of which together shall constitute one and the same instrument.

IT IS EXPRESSLY RECOGNIZED AND AGREED THAT THE PROVISIONS OF THIS AGREEMENT SHALL SURVIVE THE TERMINATION OF EACH CLASS MEMBER'S CONSULTING ENGAGEMENT WITH THE DISCLOSING CLASS MEMBER, AND SHALL REMAIN IN FULL FORCE AND EFFECT FOLLOWING THE DATE OF ANY SUCH TERMINATION.

IN WITNESS WHEREOF, the parties have executed this Confidentiality, Non-Disclosure and Development Agreement on Exhibit A effective as of the date first written above. We intend to be legally bound by the obligations set forth herein.

\section{Exhibit A}

(Class Members)

Semester, 20

We, the undersigned Class Members, hereby show by our signatures that we intend to be legally bound by the obligations set forth in the Confidentiality, Non-Disclosure and Development Agreement that this Exhibit is a part of.

\begin{tabular}{|l|l|}
\hline Name & \\
\hline & \\
\hline & \\
\hline & \\
\hline & \\
\hline & \\
\hline & \\
\hline & \\
\hline & \\
\hline & \\
\hline & \\
\hline
\end{tabular}




\section{Appendix B -Non-Disclosure Instrument (Short Form)}

\section{CONFIDENTIALITY AND NON-DISCLOSURE AGREEMENT}

This Confidentiality and Non-Disclosure Agreement ("Agreement") is made and entered into this day of , 20 (the "Effective Date") by and between all of the students and instructor(s) in the class as set forth in Exhibit A to this Agreement (collectively, "Class Members").

1. We, the Class Members want to induce each other to disclose to each other potentially patentable and commercially exploitable inventions that each of us individually would otherwise not have access to so that we can all help each other. Therefore, we agree that we shall not use, directly or indirectly, and shall hold in strict confidence and refrain from disclosing to others, except to other Class Members for the benefit of the Disclosing Class Member, the Confidential Information of the Disclosing Class Member. We define a fair and reasonable meaning of Confidential Information to be the following:

a. "Confidential Information" shall be deemed to include, but shall not be limited to, specifications, drawings, models, pictures, videos and PowerPoint presentations depicting part or all of the Disclosing Class Member's invention, trade secrets, data, products, operational methods, technical processes, techniques, information, source codes, object codes, executables, software, and/or any other information of the Disclosing Class Member or which the Disclosing Class Member uses or may use in practicing the Disclosing Class Member's invention, but shall exclude information which:

(1) was already known to the other Class Members prior to this Agreement;

(2) becomes generally available to the public other than through a breach of this Agreement;

(3) is furnished to the other Class Members by a third party who is lawfully in possession of such information and who lawfully conveys that information; or

(4) is required to be disclosed by law, court order or other legal means.

2. We recognize that if we publicize any Confidential Information, we jeopardize the patentability of our fellow Class Members' inventions. Therefore, in order to induce our fellow Class Members to tell us about their ideas and inventions we agree to not post any Confidential Information on any Internet web site, social networking site (including, but not limited to, Facebook and My Space) and not to disseminate or publish Confidential Information outside the Class via text message, e-mail, cell phone photo, photocopy or by any other means whatsoever.

3. All Class Members agree that each Class Member owns all the rights to his or her own invention and none of us acquires any right to another Class Member's invention just because we help with it or come up with a better idea regarding how it should work. We therefore agree that all Confidential Information and intellectual property made or conceived by 
any Class Member, regarding the Disclosing Class Member's invention, is the sole property of the Disclosing Class Member. Nothing in this Agreement grants to Class Member any license or other rights in or to the Confidential Information of the Disclosing Class Member. In order to implement this, we all agree that the "work for hire" doctrine applies to whatever is made or conceived by any of us regarding the Disclosing Class Member's invention. This means that:

The Class Members agree that all of the Class Members' work-product on the invention of the Disclosing Class Member is the result of work for hire and, as such, all discoveries, inventions, improvements, ideas, devices, writings or other intellectual property which Class Members shall make or conceive solely or jointly with others in the course or scope of the class, and including all work-product with the look, feel and touch of any program invented by the Disclosing Class Member, shall be the sole and exclusive property of the Disclosing Class Member without further compensation.

We understand that U.S. patent applications have to be filed in the name of the true inventor (or inventors, if there are more than one inventor). Therefore, should we become joint inventors in the eyes of the law with another due to how events unfold, we agree that if a Disclosing Class Member wants to file a patent application covering his or her invention, we will sign it, if necessary and we shall and hereby do assign to the Disclosing Class Member all right and title to such patent application, provided that all fees and costs associated with preparing the application and assignment are paid solely by the Disclosing Class Member.

4. Everything that we have agreed to is in this writing. This Agreement may only be changed if everyone who is affected by the change agrees to it in writing.

5. This Agreement may be executed in any number of multiple counterparts with the same effect as if the signatures thereto and hereto were upon the same instrument. Each such counterpart shall be deemed an original, but all of which together shall constitute one and the same instrument.

IT IS EXPRESSLY RECOGNIZED AND AGREED THAT THE PROVISIONS OF THIS AGREEMENT SHALL SURVIVE THE TERMINATION OF THIS CLASS AND SHALL REMAIN IN FULL FORCE AND EFFECT FOLLOWING THIS CLASS.

We, the Class Members, have signed this Confidentiality and Non-Disclosure Agreement on Exhibit $\mathrm{A}$ and intend for it to be effective as of the date shown in the first paragraph. We intend to be legally bound by the obligations set forth herein. 


\section{Exhibit A}

\section{(Class Members)}

Semester, 20

We, the undersigned Class Members, hereby show by our signatures that we intend to be legally bound by the obligations set forth in the Confidentiality and Non-Disclosure Agreement that this Exhibit is a part of.

\begin{tabular}{|l|l|}
\hline Name & \multicolumn{1}{c|}{ Signature } \\
\hline & \\
\hline & \\
\hline & \\
\hline & \\
\hline & \\
\hline & \\
\hline & \\
\hline & \\
\hline & \\
\hline & \\
\hline
\end{tabular}

